\title{
The diagnosis and surgical management of major salivary gland pathology
}

\author{
B Lawler,* A Pierce,† PJ Sambrook,‡ RHB Jones,ł AN Gossł
}

\begin{abstract}
Background: Major salivary gland pathology is an uncommon but important finding which may initially present to general dental and medical practitioners. The consequences of misdiagnosis are important, as acute obstruction and neoplasia are the main pathological lesions diagnosed. The purpose of this study was to analyze a consecutive series of major gland pathologies treated surgically to determine diagnostic and treatment problems.

Methods: A retrospective analysis of all cases of the major salivary glands treated on an inpatient surgical basis over a five-year period by the Oral and Maxillofacial Surgery Unit of the Royal Adelaide Hospital was performed. Particular emphasis was placed on the referring diagnosis as compared to the final diagnosis.

Results: Fifty-four patients had surgical management of 62 major salivary glands over the five-year period. By gland, 18 (33.3 per cent) were parotid, 35 (51.1 per cent) submandibular and nine (16.6 per cent) were sublingual. Fifty-one (82 per cent) of all lesions were inflammatory and 11 (18 per cent) neoplastic. The most common presentations were swelling (72 per cent) and pain (33 per cent). Most patients were referred by general dentists ( 37 per cent), followed by general medical practitioners (32 per cent) and specialists ( 28 per cent). The referring diagnosis was correct for only 45 per cent of the dentists but 76 per cent for the general medical practitioners and 87 per cent for the specialists. Only two of the 11 gland neoplasms were correctly identified as neoplasms, both by specialists. The morbidity of the surgical treatment was low.

Conclusion: The general dental practitioner is often the first health professional with the opportunity to assess salivary gland pathology, and therefore needs to be aware of the presenting signs and symptoms of major salivary gland lesions.
\end{abstract}

Key words: Major salivary glands, pathology, investigation, surgery.

(Accepted for publication 20 August 2003.)

*Final year student 2001, Oral and Maxillofacial Surgery Unit, The University of Adelaide, Adelaide, South Australia.

†Oral Pathologist, Oral and Maxillofacial Surgery Unit, The

University of Adelaide, Adelaide, South Australia.

$\ddagger$ Oral and Maxillofacial Surgeons, Oral and Maxillofacial Surgery

Unit, The University of Adelaide, Adelaide, South Australia.

\section{INTRODUCTION}

Diagnostic pathology of the major salivary glands is an uncommon but difficult problem for general dental practitioners. ${ }^{1}$ The usual presenting symptoms of pain and swelling are easily confused with more common problems such as temporomandibular joint disorders and odontogenic infections.

Salivary gland pathology is complex and is predominantly inflammatory or neoplastic. Inflammatory pathology may be secondary to obstruction by sialoliths or more complex autoimmune or systemic inflammatory conditions. ${ }^{2}$ Neoplastic pathology may be benign or malignant with multiple complex histologic subtypes displaying widely differing behavioural characteristics. ${ }^{3}$

The usual investigative techniques of conventional radiology with or without contrast sialography are largely non-contributory. Effective diagnostic imaging usually requires computerized tomography (CT) and/or fine needle aspiration (FNA). Frequently, the final diagnosis can only be established from the excisional pathologic specimen.

The choices for management are limited and consist of either no active treatment except observation, or surgical removal of the gland. All of the major glands are in areas of significant anatomical complexity. The parotid gland is intimately associated with the facial nerve; the submandibular gland with the facial, lingual and hypoglossal nerves, and the sublingual gland with the lingual nerve and multiple veins (Fig 1,2).

The current retrospective study examines a consecutive series of major salivary gland pathologies treated surgically by the Oral and Maxillofacial Surgery Unit of the Royal Adelaide Hospital over a five-year period (1996-2001). Particular emphasis was placed on the diagnostic process and the correlation between referral diagnosis and final diagnosis.

\section{MATERIALS AND METHODS}

The operating list records of the Oral and Maxillofacial Surgery Unit at the Royal Adelaide Hospital were examined for salivary gland surgery in the period June 1996 to June 2001. Details were 


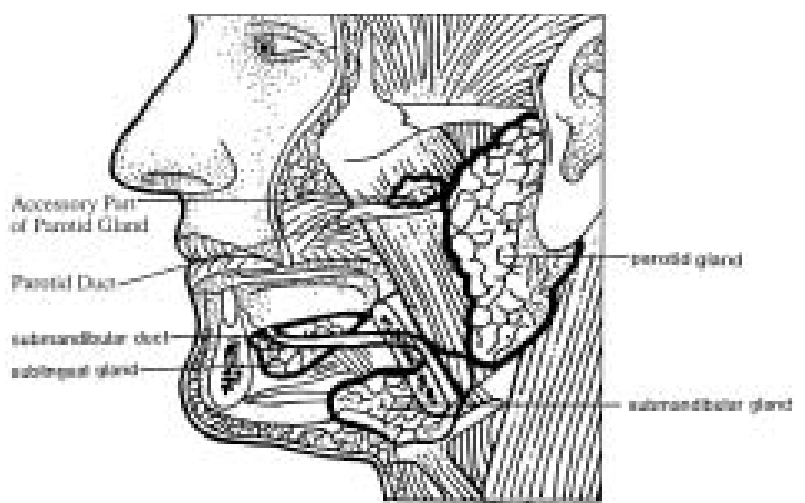

Fig 1. Diagrammatic representation of the position of the major salivary glands. (B Lawler from anatomical texts.)

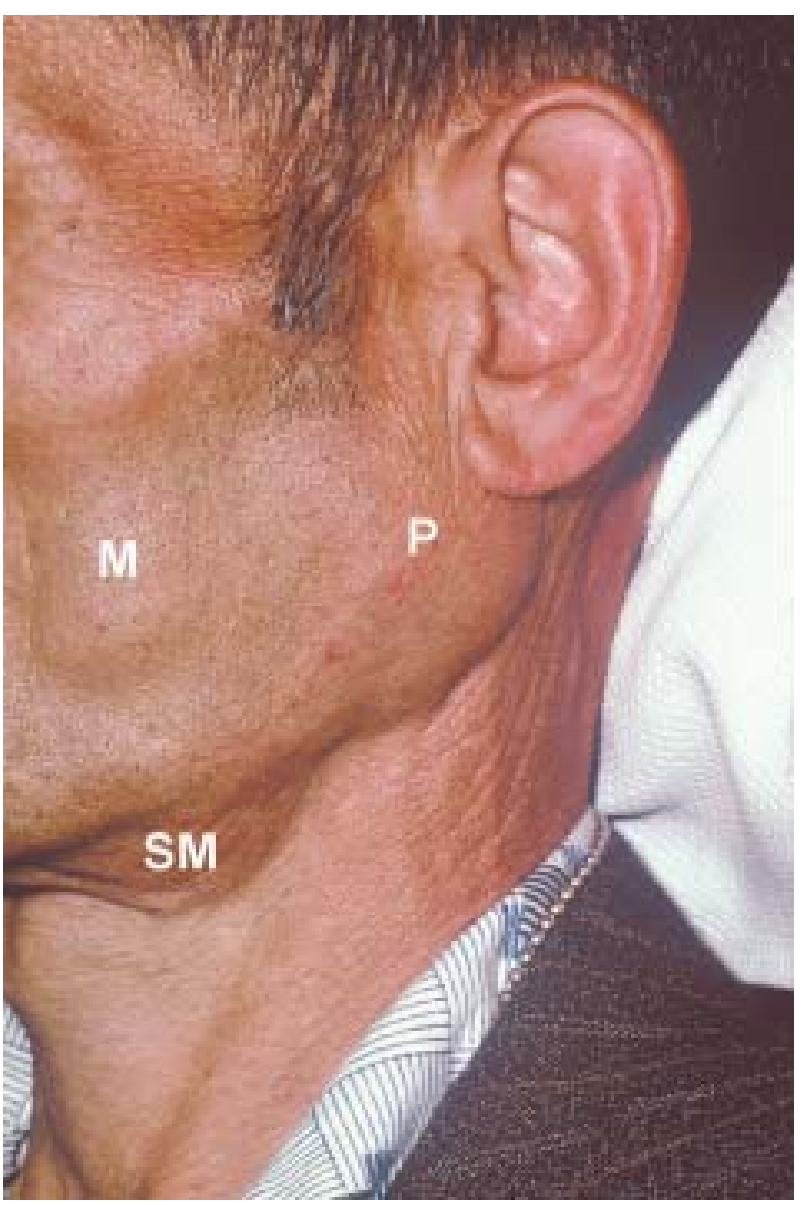

Fig 2. Enlarged parotid (P) and submandibular (SM) glands. The patient has alcoholic cirrhosis and diabetes, which results in sialosis, a benign inflammatory enlargement. This condition usually does not require surgical management. Note the prominent masseter muscle which can be confused with glandular enlargement.

transferred to a study proforma listing relevant variables.

The database was analyzed for patient demographics, referring diagnosis, investigations, final diagnosis and surgical management. Approval for the project was from the Royal Adelaide Hospital under its Quality Assurance Guidelines. At all times during the study, patient anonymity was maintained.
Table 1. Demographic features of the study population

\begin{tabular}{ll}
\hline Patients, $\mathrm{n}=$ & 54 \\
*Glands, $\mathrm{n}=$ & 62 \\
Age & Range: $14-86$ years \\
& Average: 47 years \\
$\mathrm{M}: \mathrm{F}$ & $25: 29$ \\
Parotid & $18(33.3 \%)$ \\
Submandibular & $35(51.1 \%)$ \\
Sublingual & $9(16.6 \%)$ \\
Inflammatory & 44 patients, 51 glands \\
Neoplastic & 10 patients, 11 glands
\end{tabular}

*Each gland was considered a separate case on its own.

Table 2. Presenting complaint by number of listed complaints (92)

\begin{tabular}{|c|c|c|c|c|c|c|c|c|}
\hline \multirow[t]{2}{*}{$\mathrm{n}=62$} & \multicolumn{2}{|c|}{$\begin{array}{l}\text { Total } \\
\mathrm{n}=18\end{array}$} & \multicolumn{2}{|c|}{$\begin{array}{c}\text { Parotid } \\
\mathrm{n}=35\end{array}$} & \multicolumn{2}{|c|}{$\begin{array}{c}\text { Submandibular } \\
\mathrm{n}=9\end{array}$} & \multicolumn{2}{|c|}{ Sublingua } \\
\hline & $\mathrm{n}$ & $\%$ & $\mathrm{n}$ & $\%$ & $\mathrm{n}$ & $\%$ & $\mathrm{n}$ & $\%$ \\
\hline Swelling & 39 & 63 & 14 & 78 & 18 & 51 & 7 & 78 \\
\hline Pain & 18 & 29 & 7 & 39 & 9 & 18 & 2 & 22 \\
\hline Trismus & 4 & 6 & 4 & 22 & 0 & 0 & 0 & 0 \\
\hline Eating difficulty & 3 & 5 & 0 & 0 & 2 & 6 & 1 & 11 \\
\hline Miscellaneous & 9 & 15 & 2 & 11 & 6 & 17 & 1 & 11 \\
\hline Not listed & 19 & 31 & 2 & 11 & 16 & 46 & 1 & 11 \\
\hline
\end{tabular}

The miscellaneous group included increase or decrease in salivation, sinus tracts or the salivary problem was secondary to other conditions. Table by number of glands.

\section{RESULTS}

Fifty-six cases of major salivary gland pathology surgery were identified. Two of these were discarded, as the records were grossly incomplete. Thus, this study is based on 54 patients.

The broad demographic records are presented in Table 1.

Eight patients had multiple gland involvement, with seven being inflammatory and one having two separate glandular neoplasms. Thus, this study is based on 62 separate glandular pathologies in 54 patients.

The presenting complaints are presented in Table 2 . The main presenting symptoms were swelling and pain, which was broadly similar in incidence between the different major glands. No patients had 'bad taste' as the chief complaint, but there were a range of individual complaints.

The time between the initial presentation and referral is presented in Table 3. Most patients (61 per cent) had an acute onset of symptoms and were seen within a

Table 3. Length of time patient had the chief complaint before its initial diagnosis by the referring clinician

\begin{tabular}{lrc}
\hline & $\mathrm{n}$ & $\%$ \\
\hline$<1$ week & 33 & 61 \\
$<2$ months & 6 & 11 \\
$<12$ months & 7 & 13 \\
$>12$ months (1 to 15 years) & 8 & 11 \\
Total & 54 &
\end{tabular}

Table by number of patients. 
Table 4. Referral source, by number of patients

\begin{tabular}{lrr}
\hline & $\mathrm{n}$ & $\%$ \\
\hline General dental & 20 & 37 \\
General medical & 17 & 32 \\
Specialist & 15 & 28 \\
Not recorded & 2 & 4 \\
\hline
\end{tabular}

Table 5. Investigative technique by number of patients

\begin{tabular}{lrrrrrrrr}
\hline & & & \multicolumn{5}{c}{ Accuracy } \\
\cline { 2 - 8 } & & & Correct & \multicolumn{2}{c}{ Incorrect } & \multicolumn{2}{c}{ Unknown } \\
\cline { 2 - 8 } & $\mathrm{n}$ & $\%$ & $\mathrm{n}$ & $\%$ & $\mathrm{n}$ & $\%$ & $\mathrm{n}$ & $\%$ \\
\hline Plain radiology & 46 & 85 & 38 & 83 & 5 & 11 & 3 & 7 \\
Sialography & 8 & 15 & 8 & 100 & 0 & 0 & 0 & 0 \\
Ultrasound & 8 & 15 & 7 & 88 & 1 & 12 & 0 & 0 \\
CT & 36 & 67 & 31 & 86 & 3 & 10 & 2 & 6 \\
FNA & 16 & 30 & 12 & 75 & 4 & 25 & 0 & 0
\end{tabular}

The accuracy of the test result compared to the final diagnosis. This is by patient, not gland, and most patients had several different tests.

week. In the remaining group, the patients were aware of symptoms but had taken no action.

The referral source is in Table 4. The majority of referrals were from general dental practitioners in both public and private employment. All of the medical practitioners were in private practice. The specialists included oral and maxillofacial, ear, nose and throat, and general surgeons.

The investigative techniques are presented in Table 5 . A range of tests was performed. Plain radiography was usually arranged by the referring dental or medical practitioner. Sialography and ultrasound were most commonly organized by referring medical practitioners. Computerized tomography and FNA were normally organized within the Oral and Maxillofacial Surgery Unit.

The details for the parotid glands are presented in Table 6. The incidence of neoplastic disease was almost equal to that of inflammatory pathology. The malignant cases were all presented at the Head and Neck Consultative Clinic or the Lymphoma Consultative Clinic of the Royal Adelaide Hospital and had appropriate multidisciplinary management.
Table 7. Surgical complications occurred in 26 (44\%) of the 62 glands operated on

\begin{tabular}{|c|c|c|c|c|c|c|c|c|}
\hline & \multicolumn{4}{|c|}{$\begin{array}{l}\text { Parotid Submandibular } \\
\mathrm{n}=18 \quad \mathrm{n}=35\end{array}$} & \multicolumn{2}{|c|}{$\begin{array}{c}\text { Sublingual } \\
\mathrm{n}=9\end{array}$} & \multicolumn{2}{|c|}{$\begin{array}{l}\text { Total } \\
\mathrm{n}=62\end{array}$} \\
\hline & $\mathrm{n}$ & $\%$ & $\mathrm{n}$ & $\%$ & $\mathrm{n}$ & $\%$ & $\mathrm{n}$ & $\%$ \\
\hline Patients, $\mathrm{n}=$ & 7 & 39 & 15 & 43 & 4 & 44 & 26 & 42 \\
\hline Post-operative infection & 2 & 11 & 3 & 9 & 1 & 11 & 6 & 10 \\
\hline Nerve Injury & 4 & 22 & 9 & 26 & 2 & 22 & 15 & 24 \\
\hline - Temporary & 3 & 17 & 7 & 20 & 2 & 22 & 12 & 19 \\
\hline - Permanent & 1 & 6 & 2 & 6 & 0 & 0 & 3 & 5 \\
\hline Other & 1 & 6 & 2 & 6 & 0 & 0 & 3 & 5 \\
\hline Return of lesion & 0 & 0 & 1 & 3 & 1 & 11 & 2 & 3 \\
\hline
\end{tabular}

Table 8. Initial diagnosis versus final diagnosis by gland

\begin{tabular}{lrrcc}
\hline & & Correct & Incorrect & Accuracy \\
\cline { 2 - 5 } Gland & $\mathrm{n}$ & $\mathrm{N}$ & $\mathrm{n}$ & $\%$ \\
\hline Parotid & 18 & 8 & 10 & 44 \\
Submandibular & 35 & 24 & 11 & 69 \\
Sublingual & 9 & 5 & 4 & 56 \\
Total & 62 & 37 & 25 & 60
\end{tabular}

If no diagnosis was offered in the referral letter, then this was counted as an incorrect diagnosis.

The details for the submandibular gland are presented in Table 6. The submandibular gland pathology was mainly inflammatory, secondary to obstruction by salivary calculi.

The details for the sublingual gland are presented in Table 6. All the sublingual gland pathology was inflammatory, consisting largely of obstruction, or extravasation of mucous. No sublingual neoplasms were noted during the study period.

The surgical outcome is presented in Table 7 . Removal of major gland pathology involves surgical dissection in areas of anatomical complexity. Thirty-six (58 per cent) of the series had no complications. In the remaining 26 (42 per cent), most had transient problems that spontaneously resolved. Three $(5$ per cent) sustained permanent nerve injuries to the facial nerve branches, and two ( 3 per cent) patients suffered a recurrence of the pathology. These recurrences related to incomplete removal of inflammatory pathology with

Table 6. Demographic features of the salivary gland lesions

\begin{tabular}{|c|c|c|c|}
\hline & Parotid & Submandibular gland & Sublingual gland \\
\hline Patients & $\mathrm{n}=15$ & $\mathrm{n}=31$ & $\mathrm{n}=8$ \\
\hline Glands & $\mathrm{n}=18$ & $\mathrm{n}=35$ & $\mathrm{n}=9$ \\
\hline \multirow[t]{2}{*}{ Age } & Range: $21-85$ years & Range: $14-86$ years & Range: $21-49$ years \\
\hline & Average: 52 years & Average: 51 years & Average: 38 years \\
\hline$M: F$ & $7: 11$ & $19: 16$ & $2: 7$ \\
\hline $\mathrm{R}: \mathrm{L}$ & $10: 8$ & $16: 9$ & $2: 7$ \\
\hline Inflammatory & $\begin{array}{l}10\{7 \text { obstruction } \\
\{3 \text { infection }\end{array}$ & $\begin{array}{l}32\{24 \text { obstruction } \\
\{8 \text { infection }\end{array}$ & $\begin{array}{l}9\{6 \text { mucoceles } \\
\{3 \text { extravasation }\end{array}$ \\
\hline Neoplastic & $\begin{array}{l}8\{4 \text { benign } \\
\text { - } 2 \text { pleomorphic adenoma } \\
\text { - } 1 \text { Warthins tumour } \\
\text { - } 1 \text { neurilemoma } \\
\text { - } 4 \text { malignant } \\
\text { - } 3 \text { lymphoma } \\
\text { - } 1 \text { SCC }\end{array}$ & $\begin{array}{l}3\{1 \text { benign } \\
\text { - } 1 \text { pleomorphic adenoma } \\
\{2 \text { malignant } \\
\text { - } 2 \text { Adenocarcinoma }\end{array}$ & 0 \\
\hline
\end{tabular}


Table 9. Accuracy of final diagnosis by referral source

\begin{tabular}{lcccc}
\hline & & Correct & Incorrect & Accuracy \\
\cline { 2 - 5 } Referral Source & $\mathrm{n}$ & $\mathrm{n}$ & $\mathrm{n}$ & $\%$ \\
\hline General dental & 20 & 9 & 11 & 45 \\
General medical & 17 & 13 & 4 & 76 \\
Specialist & 15 & 13 & 2 & 87 \\
Total & 52 & 35 & 17 & 71
\end{tabular}

The two where the referral source was not recorded were not included.

a recurrence of mucous extravasation in one sublingual and one submandibular specimen. No neoplastic condition recurred in the time period of the study.

The accuracy of the initial diagnosis as compared to final diagnosis is presented in Table 8. The initial diagnosis at referral was correct in 37 (60 per cent) of cases. The parotid and sublingual glands presented the most difficulty. The majority of incorrectly diagnosed cases consisted of neoplastic parotid cases that were initially diagnosed as inflammatory.

The accuracy of diagnosis by referral source is presented in Table 9. Referring dentists offered correct diagnoses in 45 per cent of cases, medical practitioners in 76 per cent of cases, and specialists were accurate in 87 per cent of cases.

\section{DISCUSSION}

This study demonstrated that major salivary gland pathology presents a diagnostic challenge to general dental practitioners, with only 45 per cent of referring dentists offering correct diagnoses. None of the salivary gland neoplasms were correctly identified by dental referrers. The most common major salivary gland

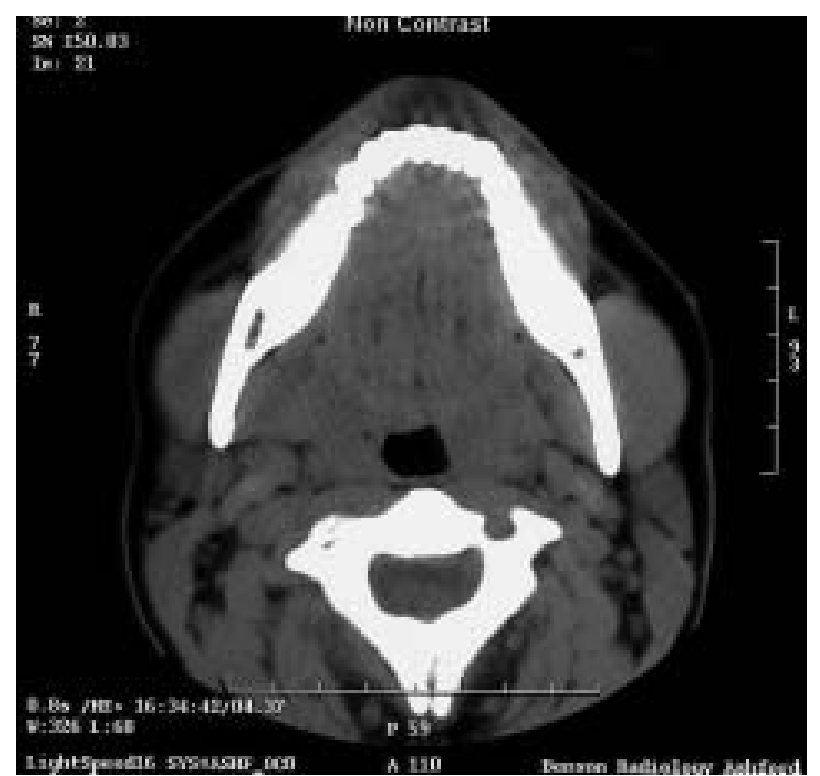

Fig 3. CT scan showing asymmetrical masseter muscles. The patient presented with a swollen left face to her general medical practitioner who suspected a benign parotid tumour. Ultrasound and FNS were performed but were normal. On OMS referral a unilateral benign masseteric hypertrophy was diagnosed and confirmed by CT.

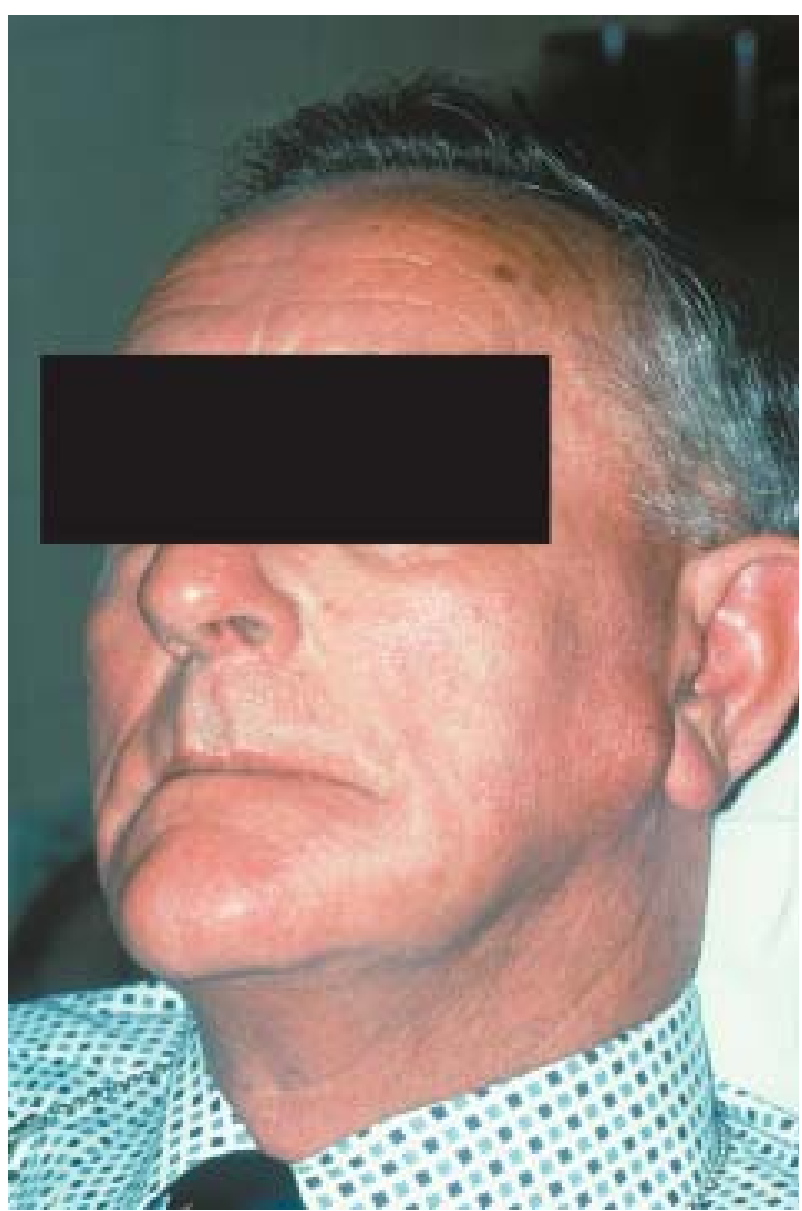

Fig 4. Pleomorphic adenoma lower pole left parotid. Note the elevation of the ear lobe.

pathologies were suspected to be temporomandibular joint problems, or acute dental infections.

The converse of this is that medical practitioners often err on the side of diagnosing parotid pathology when in fact it is a temporomandibular disorder (Fig 3).

This study also showed that major salivary gland pathologies are not rare, with the Oral and Maxillofacial Surgery Unit averaging one surgical case per month over a five-year period. This is an underestimate of the true incidence, as other surgical disciplines (including general surgery, otorhinolaryngology, and plastic surgery) also surgically manage major salivary gland pathology. Furthermore, we did not study patients treated non-surgically, or those whose surgery was performed on an outpatient or day stay basis. This would include removal of superficial stones, dilation of ducts or minor extravasation from sublingual glands. Similarly, when a normal gland was removed as part of a procedure for other pathology, for example neck dissection for oral cancer, the case was not included in the study. If such cases are included, then major salivary gland pathology is managed on a weekly basis.

The key first step in any diagnostic process is a careful history and examination. Salivary gland obstruction has a classical history of pain and swelling on eating with a tender enlarged gland. ${ }^{4}$ Other 


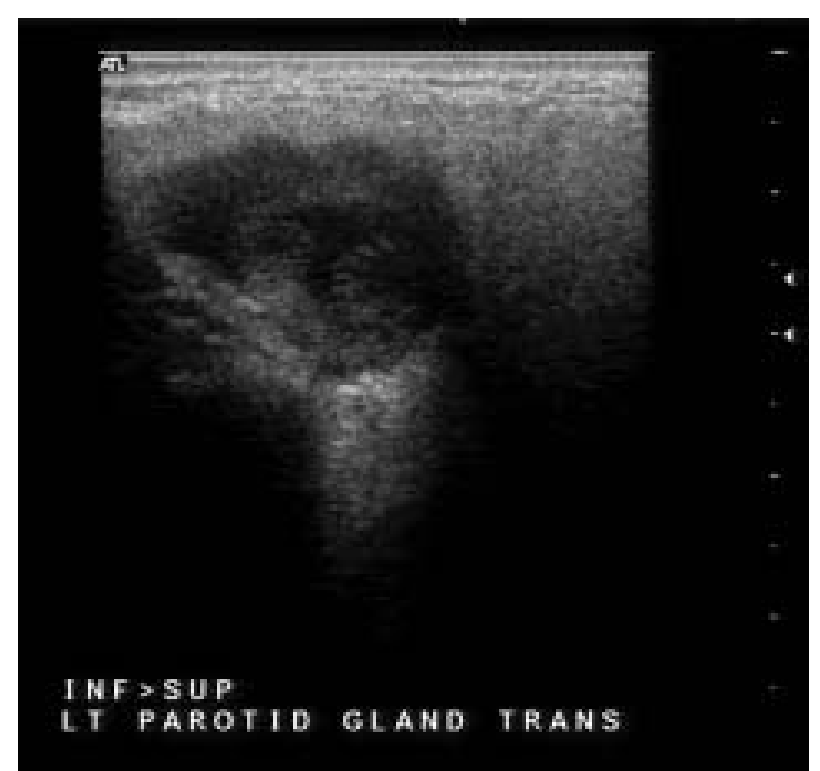

Fig 5. Ultrasound benign tumour parotid. The dark central area is the tumour, the surrounding white area the gland. Ultrasound

shows whether a discreet pathology is present and its size.

inflammatory conditions of the glands involve persistent pain and tenderness that is different to masticatory muscle spasm. It usually involves more than one gland and other connective tissue disorders are present. Neoplastic glands are enlarged and are usually painless until the late stages. ${ }^{2}$

The classic pathology of parotid glands is benign neoplasms such as pleomorphic adenoma or Warthins tumour $^{5}$ (Fig 4, 5, 6). In the current series, four of 18 parotid glands were benign. Two were pleomorphic adenoma, one a Warthins tumour and one a neurilemmoma, which is an uncommon nerve tumour.

There was only one epithelial parotid malignancy, which was an undifferentiated squamous cell carcinoma arising in the parotid gland. Malignant tumours normally only account for 15 to 32 per cent of parotid tumours.

The remaining three malignancies were all lymphomas (Fig 7). Excision was both to debulk the lesion and to arrive at a final diagnosis. These were of different types: one the first manifestation of Hodgkin's disease, the second a MALT lymphoma, and the final case a lymphomamatous proliferative lesion, or Castleman's disease. ${ }^{6}$ All lymphoma cases were presented at the Lymphoma Consultative Clinic at the Royal Adelaide Hospital and subsequently managed by the medical oncologists with chemotherapy.

The inflammatory pathologies of the parotid gland included seven acute obstructions, many of which had recurred on several occasions prior to surgical removal (Fig 8, 9). No parotid calculi were demonstrated preoperatively or on subsequent histopathologic examination.

Three further cases presented with persistent swelling and pain without obstruction. Histologically, Australian Dental Journal 2004:49:1

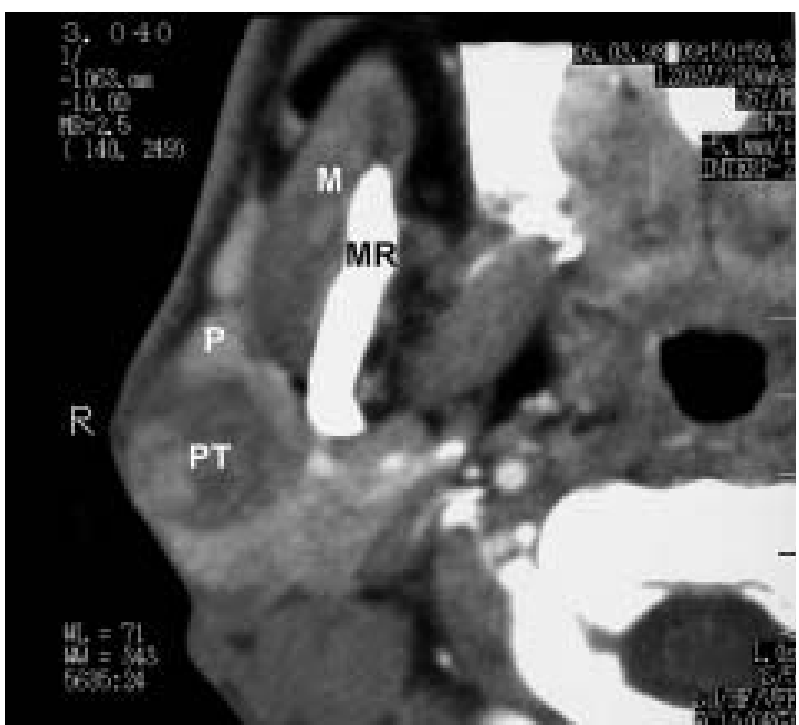

Fig 6. CT scan, axial plane. Benign parotid tumour (PT) posterior to displaced normal parotid tissue $(\mathrm{P})$, masseter muscle $(\mathrm{M})$ and the mandibular ramus (MR).

generalized inflammatory change was evident throughout the superficial lobe of the parotid gland.

The classic pathology of submandibular glands is acute obstruction by calcified stones or sialoliths (Fig 10, 11, 12). Twenty-four of the 35 submandibular glands were removed for this reason. All presented with several episodes of acute pain on eating. Some appeared clinically to have sialoliths only within the submandibular duct, but were shown subsequently on CT scanning to have multiple sialoliths within the body of the submandibular gland. It was concluded that, prior to removal of duct stones, CT examination should be undertaken to ensure that there is not generalized stone formation.

Generalized inflammatory enlargement was seen without calcified stones in a further eight cases of submandibular gland pathology.

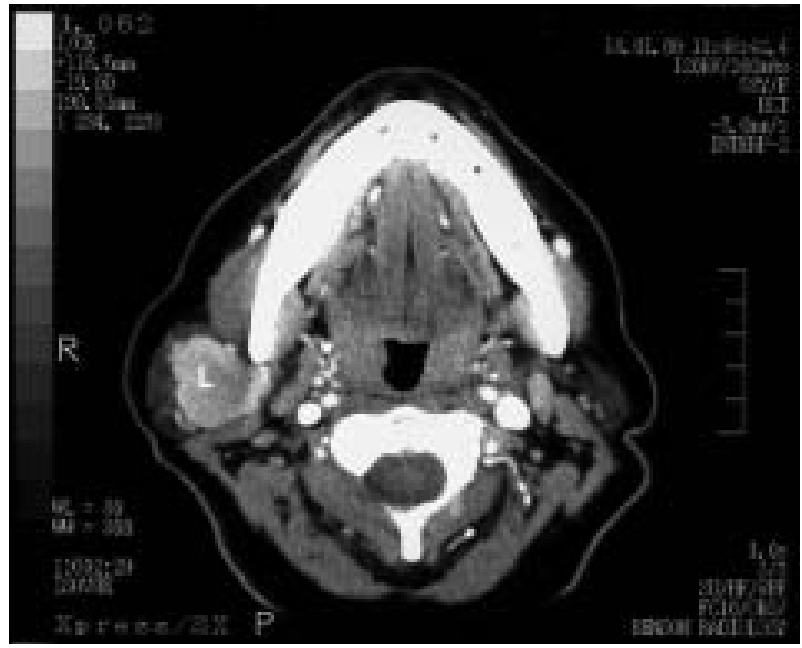

Fig 7. Lymphoma replacing the right parotid gland. These arise from lymph glands which are normally within the parotid gland. 


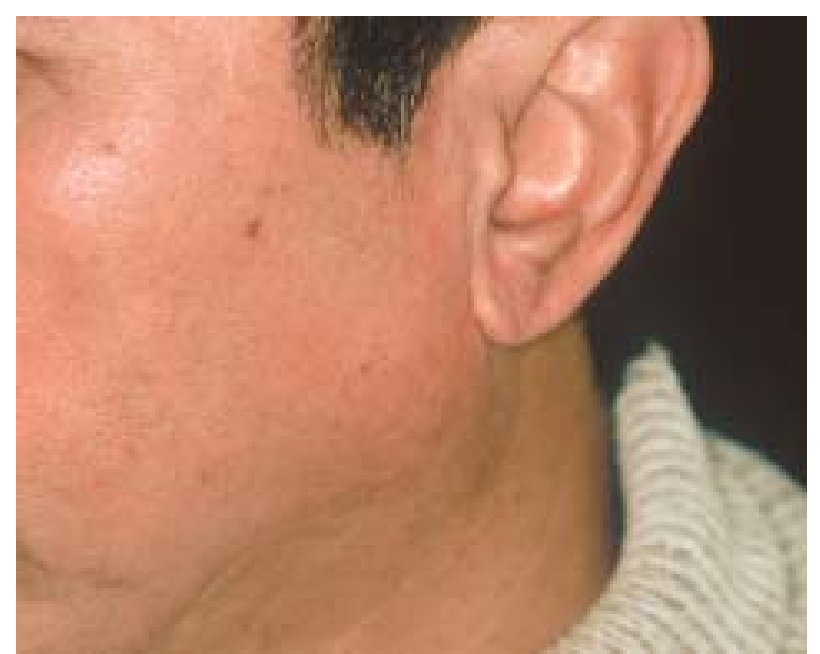

Fig 8. Diffuse enlargement of the parotid gland. This was acute and painful and consistent with acute obstruction.

Neoplastic disease is less common in submandibular glands with an equal distribution between benign and malignant $^{3}$ (Fig 13). In this series, there was one benign tumour, a pleomorphic adenoma and two adenocarcinomas. No mucoepidermoid carcinomas or adenocystic carcinomas were identified over the time period of the study.

Sublingual gland pathologies are classically mucoceles (Fig 14). These are usually well localized and simple to remove as an outpatient or on a day-stay basis. Thus, these are under-represented in this series as only extensive mucoceles, ${ }^{6}$ or those showing extravasation widely into the floor of the mouth ${ }^{3}$ were included.

Although no sublingual neoplasms were detected in this series, two cases occurred in the six months following the completion of this study. One was a mucoepidermoid carcinoma (which is the classic tumour of sublingual glands ${ }^{1}$ ) and the other was a

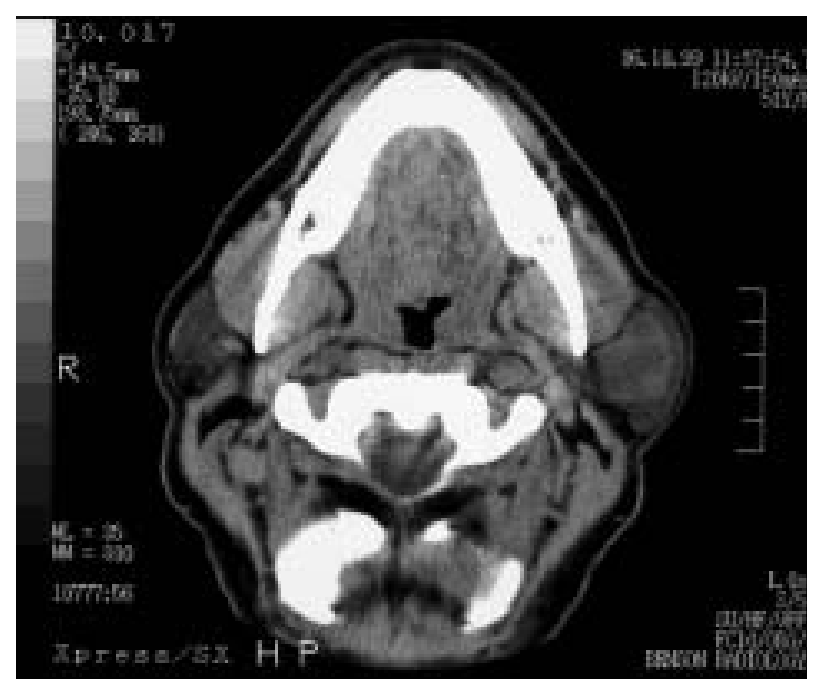

Fig 9. CT of patient in Fig 8. There is homogenous enlargement of the left gland as compared to the right. There is no evidence of calculi.

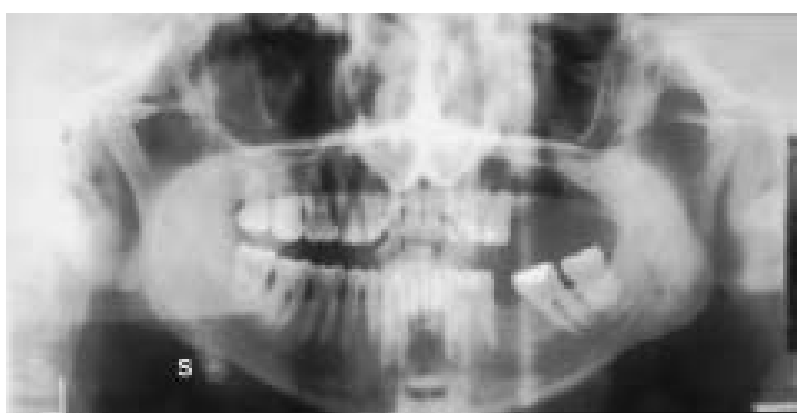

Fig 10. OPG showing a right submandibular gland sialolith (S). This was asymptomatic.

papillary cystadenoma which presented as a large mucous extravasation.

The nature of investigative procedures for major salivary gland pathology has altered over the past 10 to 20 years. It is apparent that once the history and examination has been completed, the broad nature of the pathology should be better defined, thereby suggesting the appropriate investigations.

Most of the patients in the current study had plain radiographs taken by the referrer. These have a place in the diagnosis of larger sialoliths but are not definitive. Not infrequently, clear evidence of the calculi can be detected on reviewing past radiographs. All orthopantomograms should be examined for the presence of calculi, whether the patient has symptoms or not.

Sialograms, although still mentioned by most texts, ${ }^{1}$ are really an historic investigation. They are technically difficult to perform and are painful to the patient. Furthermore, they generally only illustrate the duct system and not the gland proper. Nevertheless, in the eight cases in which sialograms were used in the present study, the pathologies present were accurately demonstrated.

Ultrasound has a place in diagnosis of major salivary gland pathology, particularly where large masses are present. ${ }^{7}$ These procedures are simple and painless, but are not diagnostic for fine parenchymal changes. Our

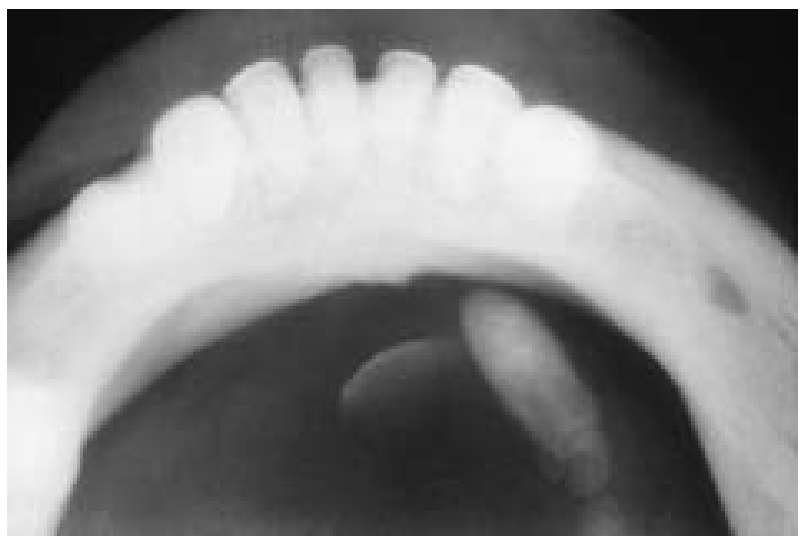

Fig 11. Occlusal radiograph showing large left submandibular duct sialolith.

Australian Dental Journal 2004;49:1. 


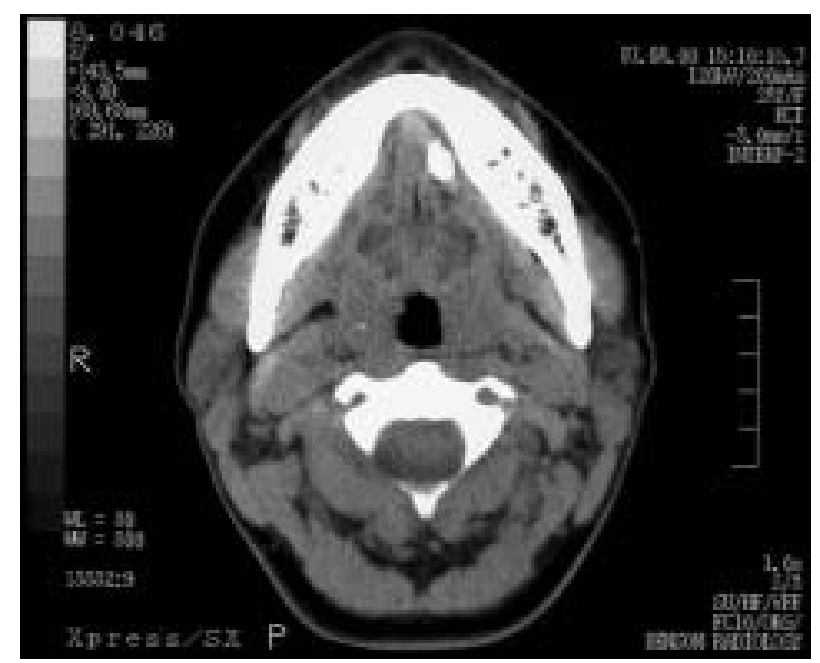

Fig 12. CT scan axial plane of Fig 12. The gland on inferior slice to this was enlarged as contained multiple stones.

preferred investigations for the diagnosis of major salivary gland pathology are a CT scan and an FNA. This combination will usually give a clear and accurate presentation of the location and character of the pathology. Magnetic resonance imaging is also accurate and less invasive for diagnostic location of major salivary gland tumours. ${ }^{8}$

\section{CONCLUSION}

This paper reviews a large consecutive series of major salivary gland pathologies which required

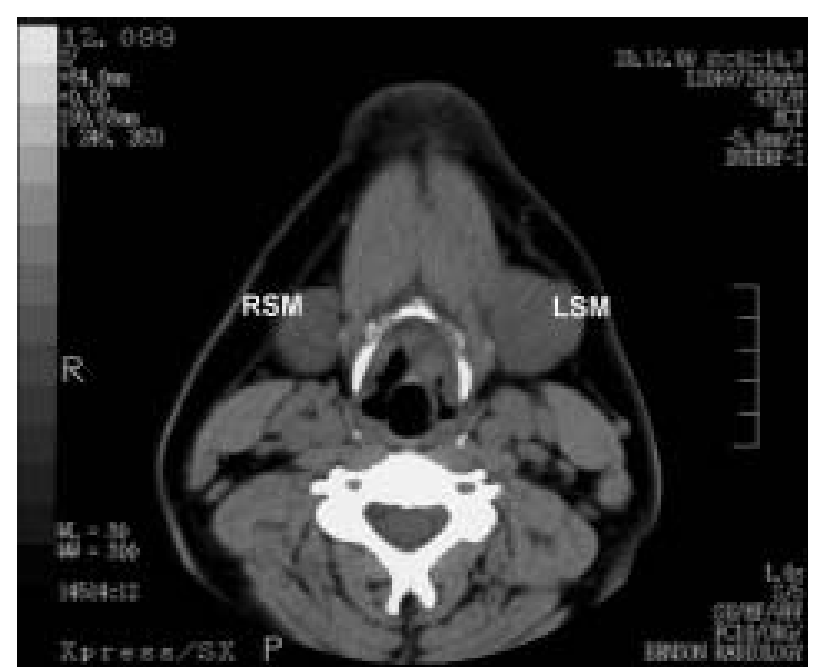

Fig 13. CT scan axial plane showing markedly enlarged left submandibular gland (LSM) as compared to the right (RSM). This was a benign pleomorphic adenoma.

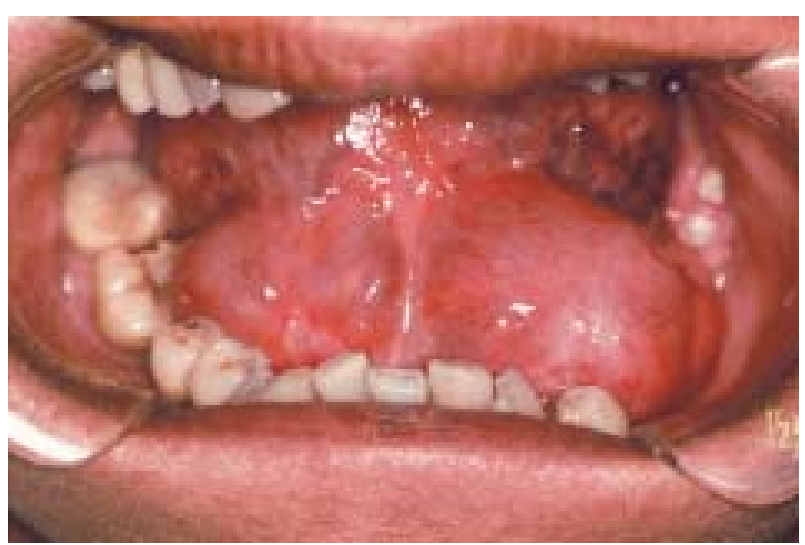

Fig 14. Large mucocele of the left sublingual gland with extension across the midline.

inpatient surgical excision. The investigations used to make an appropriate pre-operative diagnosis are presented, with a view to improving diagnostic accuracy, especially for the general dental practitioner who needs to be aware of the presenting signs and symptoms of major salivary gland lesions.

\section{REFERENCES}

1. Cawson RA. Essentials of Dental Surgery and Pathology. 4th edn. London: Churchill Livingstone, 1984:298-311.

2. Regezi JA, Sciubba JJ. Oral Pathology, Clinical Pathologic Correlations. 3rd edn. Philadelphia: WB Saunders, 1999:239.

3. Ellis GL, Auclair PL. Tumors of the Salivary Glands. Atlas of Tumor Pathology, 3rd Series, Fascicle 17. Washington DC: Armed Forces Institute of Pathology, 1996:31.

4. Cawson RA, Binnie WH, Barrett AW, Wright JM (eds). Oral disease. Clinical \& pathological correlations. 3rd edn. Edinburgh: Mosby, 2001:167.

5. Eneroth CM. Salivary gland tumors in the parotid gland, submandibular gland, and the palate region. Cancer 1971;27:1415-1418.

6. Ioachim HL. Lymph Node Pathology. 2nd edn. Philadelphia: JB Lippincott Co, 1994:236-243.

7. Corr P, Cheng P, Metreweli C. The role of ultrasound and computed tomography in the evaluation of parotid masses. Australas Radiol 1993;37:195-197.

8. Casselman JW, Mancuso AA. Major salivary gland masses: comparison of MR imaging and CT. Radiology 1987;165:183189.

Address for correspondence/reprints: Professor AN Goss Oral and Maxillofacial Surgery Dental School

The University of Adelaide Adelaide, South Australia 5005 Email: oral.surgery@adelaide.edu.au 